\section{The intra and extra cranial veins in relationship with chronic migraine}

\author{
Ginevra Toma, ${ }^{1,2}$ Paolo Onorati, ${ }^{1,2}$ \\ Giovanni Bellagamba, ${ }^{2}$ \\ Mario Vernetti Prot, ${ }^{1}$ \\ Tommaso Lupattelli ${ }^{2}$ \\ ${ }^{1}$ Department of Physiology and \\ Pharmacology "V. Erspamer", \\ La Sapienza University; \\ ${ }^{2}$ ICC Casalpalocco GVM Sanità, \\ Roma, Italy
}

\section{Background}

Migraine with and without aura is a widespread disease characterized by recurrent pain involving only one side of the head matched by nausea, vomiting, photophobia and/or hyperacusia. ${ }^{1}$ It is defined as chronic if present for at least 15 days/month for more than 3 months.

\section{Methods}

From 2013 to 2019,30 persons were examined (13 males, 17 females, mean age $43 \mathrm{yrs}, \mathrm{SD} \pm 18.57$ ) diagnosed with chronic cerebrospinal venous insufficiency (CCSVI) and migraine; 7 underwent jugular balloon angioplasty. 15 performed an intracranial MRI venography and an Echo Colour Doppler $(\mathrm{ECD})^{2}$ of the Internal Jugular Veins (IJV) ${ }^{3,4}$ resulting positive for venous anomalies and stenosis; 11 per- formed an intracranial MRI venography with positive results for venous anomalies; 4 performed ECD of IJV, resulting positive for stenosis. Of the people observed, 23 are in medical-treatment, and 7 underwent jugular balloon angioplasty.

\section{Results}

In this group, abnormalities of the cranial venous circulation are associated with chronic migraine.

In 3 persons ( 2 males, mean age $16 \mathrm{yrs}$ ) with cyclical vomiting associated with migraine, it was found: in 2 positivity both to the MR venography and to the ECD, 1 was negative to MR venography, but positive to the ECD. Of this subgroup, 2 underwent balloon angioplasty of the IJV with symptom improvements.

In 5 persons ( 4 females, mean age 45 yrs) with migraine, it was found: positivity in both the MR venography and the ECD, 1 did not perform MR venography, but was positive ECD. All 5 underwent jugular balloon angioplasty as a therapy for CCSVI with symptom improvements in 4 .

\section{Conclusions}

These preliminary observations suggest the hypothesis of a possible association between migraine and intra and extra cranial venous anomalies. ${ }^{4}$ Further studies will be needed, to verify the efficacy of jugular angioplasty as an additional therapy for chronic migraine.
Correspondence: Ginevra Toma, Department of Physiology and Pharmacology "V. Erspamer", La Sapienza University; ICC Casalpalocco GVM Sanità, Roma, Italy. E-mail: ginevra.toma@uniroma1.it

Key words: Neurovascular diseases; meeting.

Conference presentation: $9^{\text {th }}$ Annual Meeting of the International Society of Neurovascular Disease (ISNVD), May $30^{\text {th }}-31^{\text {st }}, 2019$, Ferrara, Italy.

This work is licensed under a Creative Commons Attribution 4.0 License (by-nc 4.0).

C Copyright: the Author(s), 2019

Licensee PAGEPress, Italy

Veins and Lymphatics 2019; 8:8435

doi:10.4081/vl.2019.8435

\section{References}

1. Barbanti P, Aurilia C, Egeo G, et al. Chronic migraine: treatability, refractoriness, pseudo-refractoriness. J Headache Pain 2015;16 (Suppl 1):A39.

2. Menegatti E, Tessari M, Vannini ME, et al. High resolution M-mode evaluation of jugular vein valves in patients with neurological and neurosensory disorders. Curr Neurovasc Res 2017;14:31622.

3. Zamboni P. How to objectively assess jugular primary venous obstruction. Veins and Lymphatics 2014;3:4195.

4. Louveau A, Herz J, Alme MN, et al. CNS lymphatic drainage and neuroinflammation are regulated by meningeal lymphatic vasculature. Nat Neurosci 2018;21:1380-91. 